An account of the general theoretical and experimental background is followed by two central chapters dealing with the relationship between proton shifts and chemical structure. The information summarized here will be of immense value to structural chemista, and it is likely that the carefully assembled tables will form part of the intellectual furniture of organic laboratories for a considerable time: in fact, the exposition and illustration of factors governing the chemical shift form the strongest part of the book. Spin-spin interactions are described in a subsequent chapter wherein the position is a less happy one. The discussion ranges from examples of $A B$ coupling which are readily apprehended even in large molecules to complex cases, for example $A_{2} B_{3}$, where complete resolution can only be accomplished with great difficulty. The tendency to quote, without derivation, formulæ for the frequencies and intensities of lines in a spin multiplet is unfortunate if spin-coupling constants are to be fully exploited as instruments for structure determ. ination. It would seem that an account of electron. coupled interactions in terms that will commend themselves to organic chemists has yet to be achieved.

The book is well produced and illustrated, though misprints are fairly common. There is no doubt it will occupy a place in the bookshelves of most, if not all, organic ehemistry laboratories.

$$
\text { J. C. D. Brand }
$$

\section{WAVE MOTION OF OCEANS AND ATMOSPHERES}

Hydrodynamics of Oceans and Atmospheres

By Carl Eckart. Pp. xi +290 . (London and New York : Pergamon Press, 1960.) 63s. net.

7

HIS book has a misleading title in the sense that it is neither a balanced introduction nor a treatise on the hydrodynamics of oceans and atmospheres. The dust cover and preface hint at a narrower topic; the list of contents makes it clear. Most of modern dynamic oceanography and meteorlogy-general circulation, weather prediction, current and wind structure, interaction of wind and sea, turbulence, diffusion, internal friction-are scantily treated, if at all. In fact this book is a monograph, suitable for research workers in geophysical fluid dynamics, on wave motion in an inviscid fluid. Its approach is akin to that taken by the Norwegian school of meteorologists in their book Physikalische Hydrodynamik of 1933. Prof. Eckart considers the effects of compressibility, vertical variation of density, gravity, and Coriolis force, but not instability due to shear in the unperturbed state of equili brium. To this limited topic he applies new methods, drawn from his great experience of mathematical physics.

The perturbation equations for various basic states are set up in the opening Chapters 1-5. At the same time, the time-mean motion of the Earth's atmosphere and sea is discussed perfunctorily, and some simple stationary models for the basic state are described in Cartesian and Mercator co-ordinates. The remaining chapters, 6-17, contain an original and powerful treatment of the perturbation equations. Ray theory of geometric optics, the WentzelKramers-Brillouin approximation, and SturmLiouville theory are used for a variety of cases depending on the basic variation of density, and on the neglect or retention of the Earth's rotation and of the curvature of the geopotential surfaces. This treatment embraces and unifies much classical work on sound, internal gravity waves, Lamb waves, tides and Rossby waves.

Throughout the text are remarks claiming the importance of linear wave-motion. The arguments are broadly of three kinds : those that maintain the physical relevance of wave motion, those that deny the adequacy of other theories, and those that promote wave theory as a first step toward understanding more complicated phenomena such as turbulence. Lack of space has prevented the author from properly discussing rival theories or observations of the sea and atmosphere, so I have yet to be convinced that wave-motion is more than one of many topics important in geophysical fluid dynamics. However, to this one topic the author has made an extensive and original contribution.

P. G. Drazin

\section{MAN AND HIS ANCESTRY}

\section{Man and His Ancestry}

By Alan Houghton Brodrick. Pp. $256+16$ plates. (London: Hutchinson and Co. (Publishers), Ltd., 1960.) 35s. net.

THE recent spate of semi-popular books on man and his ancestry has given the reader a wide choice. This one is useful for reference purposes since it covers a wide field and quotes many of the sources. It includes a good many new discoveries which are not widely known outside specialist journals (for example, the post-war hominid remains from China and the Neanderthal footprints cave at Toirano) and the author has some stimulating ideas about familiar facts. There are chapters on "What is Man ?", "The Genealogy of the Apes", "The Discovery of Man's Antiquity" and others on the Australopithecines, the Pithecanthropoids, the Neanderthaloids and Homo sapiens fossils. Each chapter is divided by numerous sub-headings which help to lessen the confusion caused by rapid leaps from one subject to another.

Inevitably, Mr. Brodrick's book will be compared with Mankind in the Making by Prof. W. W. Howells ; both have appeared within the past few months and cover essentially the same ground, both are easy to read and sprinkled with anecdotes. But while Prof. Howells is a trained anthropologist who can be relied on for accuracy, the general reader (for whom Man and his Ancestry is presumably intended) will be badly misled if he accepts all Mr. Brodrick's statements.

The Australopithecines are said to have lived more than a million years ago; and the beginning of the Pleistocene is set at "about two or possibly three million years ago". The Ternifine fauna is stated to be post-Villafranchian "as the presence of Equus indicates" (Equus, of course, first appeared during the Villafranchian, as the author himself points out earlier in the book). Apart from a good many minor inaccuracies of this kind, there are more serious misinterpretations. The principles of natural selection, for example, seem to have been overlooked: "Apes do not have long arms because they live in trees, they live in trees because they have long arms". 